\title{
Percepções de enfermeiros no cuidado aos pacientes com transtornos psicóticos
}

\section{Perceptions of nurses in the care of patients with psychotic disorders}

\author{
Luciana Rodrigues dos Santos' $\bullet$ Maria Luiza Rêgo Bezerra ${ }^{2} \bullet$ Andrey Hudson Interaminense Mendes de \\ Araújo $^{3} \bullet$ Thais Martins Gomes de Oliveira ${ }^{4}$ Valéria Leonhardt ${ }^{5}$
}

\begin{abstract}
RESUMO
Objetivo: apresentar as percepções de enfermeiros no cuidado aos transtornos psicóticos por meio da literatura cientifica. Método: trata-se de uma revisão integrativa de caráter descritiva e exploratória em artigos publicados entre 2015 e 2019 na biblioteca eletrônica SciELO e na base de dados LILACS com os descritores Transtornos Psicóticos, Cuidados de Enfermagem, Saúde Mental, Enfermagem psiquiátrica. Analisaram-se os dados pela técnica de Análise de Conteúdo. Resultados: selecionaram-se 14 artigos, dos quais melhor se adequa ao objetivo da pesquisa para posterior discussão, sendo I3 artigos do tipo pesquisa de campo e I do tipo reflexão teórica. Conclusão: constaram-se que pelas percepções dos enfermeiros, a angustia, o medo, o estresse, a insegurança, a comodidade e o esgotamento, são sofrimentos que estão presentes no decorrer da assistência e que os profissionais utilizam da empatia, escuta ativa, preocupação com o paciente, olhar holístico e tentativa de reinserção do doente mental na sociedade.
\end{abstract}

Descritores:Transtornos Psicóticos; Cuidados de Enfermagem; Revisão; Brasil.

\begin{abstract}
Objective: to present nurses' perceptions in the care of psychotic disorders through scientific literature. Method: this is an integrative review of a descriptive and exploratory nature in articles published between 2015 and 2019 in the SciELO electronic library and in the LILACS database with the descriptors Psychotic Disorders, Nursing Care, Mental Health, Psychiatric Nursing. Data were analyzed using the Content Analysis technique. Results: I4 articles were selected, of which best fits the research objective for further discussion, with I 3 field research articles and I theoretical reflection type. Conclusion: it was found that due to the nurses' perceptions, anguish, fear, stress, insecurity, convenience and exhaustion, are sufferings that are present during the assistance and that professionals use empathy, active listening, concern with the patient, a holistic view and an attempt to reinsert the mentally ill in society.

Descriptors: Psychotic Disorders; Nursing Care; Review; Brazil.
\end{abstract}

I Enfermeira pela Universidade Paulista (UNIP), campus Brasília-DF.

2 Doutoranda em Bioética (UnB). Mestra em Enfermagem (UnB). Especialista em Gestão em Saúde Pública com ênfase em Saúde Coletiva e da Família (INESPO). Enfermeira (UFMA). Professora do curso de Enfermagem (Unip, campus Brasília-DF)

3 Mestre em Ciência e Tecnolgoias em Saúde - UnB. Especialista em Saúde da Família (UNESA). Enfermeiro - UnB. Professor do Curso de Enfermagem da Universidade Paulista - campus Brasília

4 Doutoranda e Mestre em Enfermagem- UnB. Especialista em Saude do Trabalho. Enfermeira - UnB. Professora do Curso de Enfermagem da Universidade Paulista campus Brasília). E-mail:

5 Graduada em Educação Física pela Faculadade de Filosofia Ciências e Letras de São José do Rio Pardo. Especialista em fisiologia do exercício pela Universidade Gama Filho - DF. Mestre em Fisiologia Humana pela Universidade Estadual do Ceará. 


\section{INTRODUÇÃO}

Os transtornos mentais são definidos como síndromes patológicas caracterizadas por confusões, delírios, alucinações e perturbações relacionadas ao conceito real das coisas existentes ${ }^{(-}$. Descreve-se pelo ramo psiquiátrico que as psicoses muitas vezes não possuem causa essencial determinada, o que dificulta o diagnóstico e a adequação do tratamento. A fuga da realidade (ou perda de noção da realidade) causa comportamentos fora de percepção, levando o indivíduo a se confinar em um mundo imaginário, ou, ao menos, irreal. Os sintomas podem ser categorizados em positivos: delírio, alucinação e fala desorganizada; e em negativos: retraimento social e embotamento afetivo. ${ }^{(2-3)}$

A Classificação Estatística Internacional de Doenças e Problemas Relacionados à Saúde 10 (CID-I0) é um sistema utilizado em diversos países e que serve como padronização de diagnóstico para os transtornos psicóticos. Esta publicação, advinda da Organização Mundial de Saúde (OMS), em seu capitulo V, refere-se aos transtornos mentais e comportamentais, cujos CIDs estão entre $\mathrm{F00}$ e F99. Desta forma, é importante atentar-se ao CID correspondente ao transtorno mental, que está estratificado em grupos: do F00 ao F09 são elencados os transtornos mentais orgânicos, inclusive os sintomáticos; do FIO ao FI9, transtornos mentais e comportamentais devido ao uso de substâncias psicoativas; do F20 ao F29, esquizofrenia, transtornos esquizotípicos e transtornos delirantes; do F30 ao F39 transtornos do humor (afetivos); do F40 ao F48, transtornos neuróticos, transtornos relacionados ao estresse e transtornos somatoformes; do F50 ao F59, síndromes comportamentais associadas a disfunções fisiológicas e a fatores físicos; do F60 ao F69 Transtornos da personalidade e do comportamento do adulto; do F70 ao F79, Retardo mental; do F80 ao F89, transtornos do desenvolvimento psicológico; do F90 ao F98, transtornos do comportamento e transtornos emocionais que aparecem habitualmente durante a infância ou a adolescência; e, por fim, o F99 que representa o transtorno mental não especificado. ${ }^{(3)}$

Deve-se pontuar que os cuidados aos transtornos mentais vão além de passos para a mitigação dos sintomas, requer etapas que reconheçam as viabilidades de participação do indivíduo nas circunstâncias do tratamento. Pessoas em ocasiões de estresse, angústia e situações incomuns ou desnorteadoras podem experimentar episódios psíquicos delicados, podendo se tornar graves, agindo de forma incompreensíveis e desequilibrando o estado mental, que podem se desenvolver a transtornos psicóticos. ${ }^{(2)}$ Os problemas de saúde mental apresentam alta prevalência, bem como níveis grandiosos de incapacidades e mortalidade. ${ }^{(4)}$

Salienta-se que o episódio psicótico agudo tem po- tencial de sucesso no tratamento, com a possibilidade de não apresentar resquícios, principalmente com o diagnóstico precoce, tratamento de forma intensiva e prevenção dos sintomas. ${ }^{(2)} \mathrm{Na}$ maioria das vezes há um fator desencadeante que leva o indivíduo a apresentar sintomas de angústia, inquietação e insônia, seguidas de delírios, alucinações visuais e auditivas, falas desorganizadas, humor preocupado, agitação psicomotora, medo e isolamento. ${ }^{(5)}$ As primeiras crises psicóticas podem ser de grande intensidade, difícil controle e potencial de incapacitação, que podem induzir a alterações físicas, biológicas e psicossociais.(6) Para amenizar a gravidade e oferecer apoio, os familiares tem crucial importância no controle e tratamento dessas crises, quando recebem orientação adequada. ${ }^{(7)}$

Partindo-se do princípio, a reforma psiquiátrica motivada pelas políticas de saúde mental, trouxe modificações no cuidado aos pacientes com transtornos mentais. ${ }^{(8)}$ Houve a necessidade de ampliação dos cuidados psiquiátricos aumentando o envolvimento familiar na assistência, com o devido comprometimento da equipe de enfermagem, aumentando seus papéis dentro dos serviços de saúde mental, o que, muitas vez, pode gerar problemas, como a sobrecarga de trabalho e demanda excessiva das unidades de saúde. ${ }^{(9)}$

Sabe-se que, dentro da Rede de Atenção à Saúde Psicossocial (RAPS), os serviços de saúde têm a atribuição de fazer o acompanhamento do paciente com transtorno mental, oferecendo todo suporte e cuidado no tratamento deste. Equipes multiprofissionais desempenham variados papéis nesta rede e é de extrema importância que o enfermeiro participe desta equipe e que, com o conhecimento sobre os transtornos mentais, este consiga suprir as necessidades de saúde, esclareça formas de abordagem e coleta de informações, desenvolva métodos de organizações das informações coletadas visando um plano de cuidados, além de identificação e proposição de intervenções e avaliação da assistência prestada. foco do cuidado ao paciente com transtorno mental deve ser dirigido ao reconhecimento do significado individual da experiência do sofrimento psíquico no seu contexto social, político e cultural, não se restringindo à sintomatologia psicopatológica e ao diagnóstico psiquiátrico, apenas. ${ }^{(10)}$

Evidencia-se que a importância dos cuidados de enfermagem nos transtornos mentais se baseia no desenvolvimento de vínculo com o paciente em tratamento, que traz segurança e cria laços, sendo extremamente necessário para o sucesso de qualquer terapêutica. É necessário que o enfermeiro ofereça escuta ativa e qualificada tornando a assistência humanizada e que cada condição que envolva o paciente, sendo um ser biológico, psíquico e sociocultural, seja vista de forma individualizada, obten- 
do através do vínculo com o paciente dados importantes, desde $o$ acolhimento. (11)

Objetiva-se com este estudo apresentar as percepções dos enfermeiros no cuidado aos pacientes com transtornos psicóticos por meio da literatura cientifica.

Configura-se que a contribuição desta revisão de literatura é em trazer considerações acerca do cuidado ao paciente com transtornos psicóticos sob a percepção da equipe de enfermagem, propiciando conhecimento mais aprofundado sobre a díade assistência $x$ cuidado.

\section{MÉTODO}

Trata-se de uma revisão integrativa de caráter descritiva e exploratória ${ }^{(26-27)}$. Definiu-se como questão norteadora: Quais as percepções de enfermeiros acerca do cuidado aos pacientes com transtornos psicóticos? A técnica de pesquisa incluiu as seguintes palavras-chaves: Transtornos Psicóticos AND Cuidados de Enfermagem AND Saúde Mental; Transtornos Psicóticos AND Cuidados de Enfermagem AND Enfermagem Psiquiátrica;Transtornos psicóticos AND Saúde Mental AND Enfermagem Psiquiátrica; e Cuidados de Enfermagem AND Saúde Mental AND Enfermagem psiquiátrica.

Incluíram-se na pesquisa os artigos publicados entre
2015 e 2019 , em idioma português e inglês, artigos científicos completos e indexados na biblioteca eletrônica SciELO (Scientific Electronic Library Online) e na base de dados LILACS (Literatura Latino-americana e do Caribe em Ciências da Saúde), conforme figura I. Excluiu-se da pesquisa os artigos publicados anteriormente a 2015 , artigos que possuíam correlação com as palavras chaves, que não contemplam a temática, que não possuem versão na língua portuguesa e inglesa, e que estão indexadas em outras bases de dados fora do campo de estudo.

Utilizaram-se para a escolha da amostra, o Cruzamento por Descritores (CD) devidamente selecionados e consultados no DeCS (Descritores em ciências da saúde). $\mathrm{Na}$ SciELO, usando a estratégia de busca associada com o operador booleano "AND", encontraramse 2 artigos com o Cruzamento por Descritores (CD) Transtornos Psicóticos AND Cuidados de Enfermagem AND Saúde Mental, representando 3,5\% do total de artigos encontrados nesta biblioteca eletrônica. Com o CD Transtornos Psicóticos AND Cuidados de Enfermagem AND Enfermagem Psiquiátrica, encontraram-se I artigo, representando apenas I,7\% do total; com o CD Transtornos psicóticos AND Saúde Mental AND Enfermagem Psiquiátrica encontraram-se 2 artigos, representando

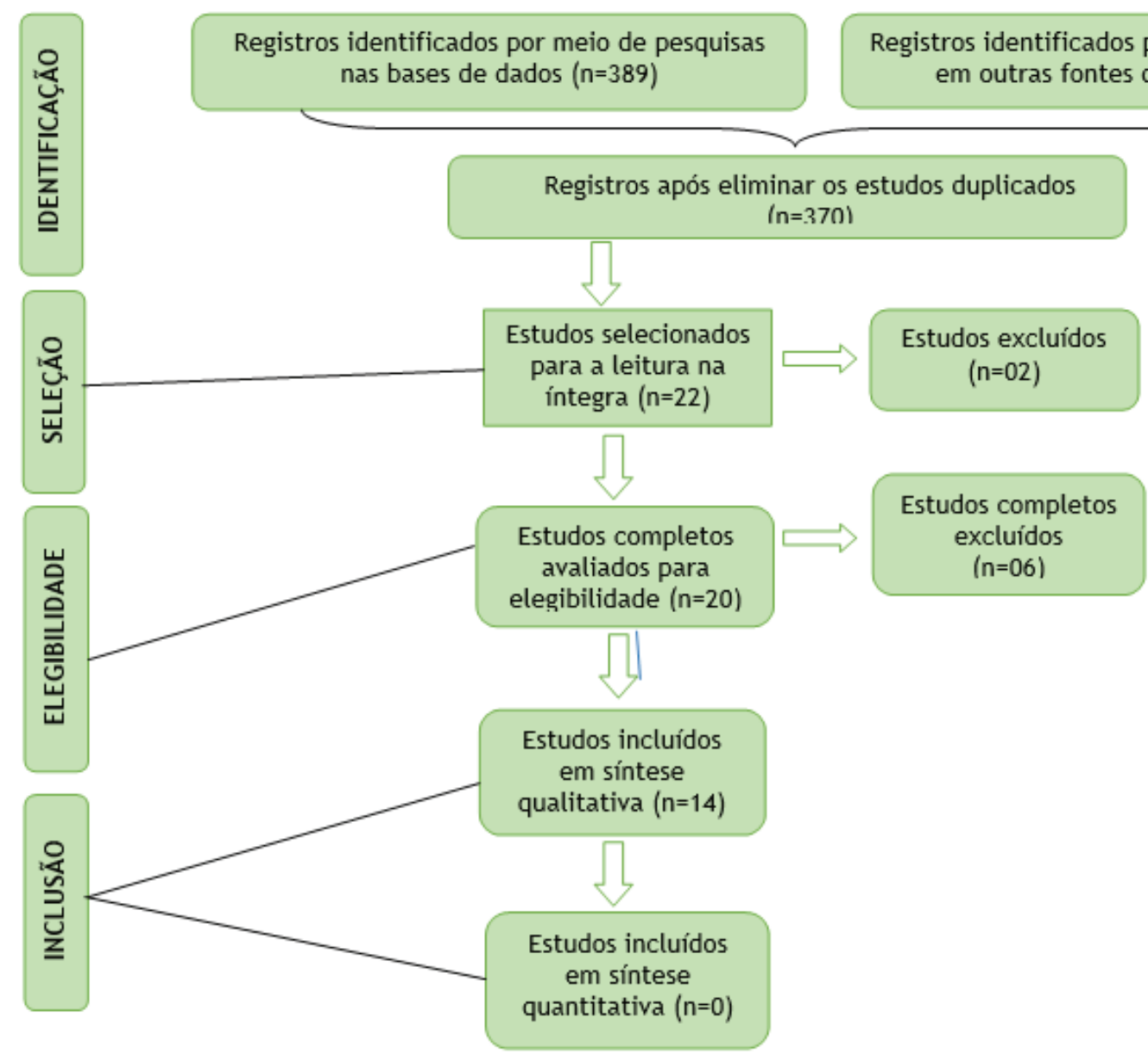

FIGURA 1 - Fluxograma do Perfil amostral da revisão bibliográfica realizada. Brasília-DF, Brasil, 2019. 
3,5\%; e, por fim, com o CD Cuidados de Enfermagem AND Saúde Mental AND Enfermagem psiquiátrica encontraram-se $5 \mathrm{I}$ artigos, representando $91 \%$ do total da amostra nesta biblioteca eletrônica. Portanto, com o uso deste operador, encontraram-se 56 artigos com variadas temáticas, objetivos e metodologias nesta plataforma.

$\mathrm{Na}$ base de dados LILACS, utilizaram-se os descritores Transtornos Psicóticos AND Cuidados de Enfermagem AND Saúde Mental e encontraram-se 10 artigos, representando 3\% do total da amostra; com o CD Transtornos Psicóticos AND Cuidados de Enfermagem AND Enfermagem Psiquiátrica, encontraram-se 4 artigos, representando I,2\%; no CD Transtornos psicóticos AND Saúde Mental AND Enfermagem Psiquiátrica encontraram-se 8 artigos (2,4\%); e com $O C D$ Cuidados de Enfermagem AND Saúde Mental AND Enfermagem psiquiátrica, encontraram-se $31 \mathrm{I}$ artigos representando $93,3 \%$ do total da amostra coletadas nesta base de dados. Totalizando, encontraram-se 333 artigos na LILACS.

Obteve-se como resultado total do processo de busca na biblioteca eletrônica SciELO e na base de dados LILACS 389 artigos, dos quais foram utilizados os filtros pertinentes aos critérios de inclusão e selecionaram-se 73 artigos para a leitura dos resumos. Após a leitura, excluíram-se os artigos que não se encaixavam nos critérios inclusivos da pesquisa e que fugiam da temática e do objeto de estudo, e foram selecionados para posterior leitura na íntegra 22 artigos, sendo 12 da SciELO e 10 da LILACS.Após a leitura, selecionaram-se 14 artigos para posterior discussão, sendo 9 da SciELO e 5 da LILACS, os quais melhor se adequam e respondem o objetivo desta pesquisa.

\section{RESULTADOS}

Salienta-se que dos 14 artigos selecionados, 13 tinham como metodologia a pesquisa de campo de abordagem qualitativa e I do tipo reflexão teórica. Em relação ao período de publicação, 3 artigos foram publicados em 2015, 2 em 2016, 4 em 20I7, 4 e 2018 e I em 20I9, o que corrobora com apenas a utilização de dados atuais nesta pesquisa. Quanto aos objetivos das pesquisas, a maioria trata de conhecer e analisar o cuidado enfermeiro-paciente na saúde mental, caracterizar as atitudes dos enfermeiros neste âmbito, refletir sobre a assistência de enfermagem em saúde mental, entre diversas outras temáticas.

Apresenta-se na figura 2 a seguir, os principais dados da amostra coletada na biblioteca eletrônica e na base de dados, em ordem decrescente do período de publicação.

\begin{tabular}{|c|c|c|c|c|}
\hline Autor/Ano & Título & Método & Objetivo & Resultado \\
\hline $\begin{array}{l}\text { Agnol, Meazza, } \\
\text { Guimarães, } \\
\text { Vendruscolo, } \\
\text { Testoni/2019.(17) }\end{array}$ & $\begin{array}{l}\text { Cuidado de enfermagem } \\
\text { às pessoas com } \\
\text { transtorno de } \\
\text { personalidade borderline } \\
\text { na perspectiva freireana. }\end{array}$ & $\begin{array}{l}\text { Pesquisa } \\
\text { qualitativa }\end{array}$ & $\begin{array}{l}\text { Compreender, } \\
\text { sob a perspectiva } \\
\text { ética de Freire, } \\
\text { o cuidado de } \\
\text { enfermagem às } \\
\text { pessoas com } \\
\text { transtorno de } \\
\text { personalidade } \\
\text { borderline. }\end{array}$ & $\begin{array}{l}\text { Emergiram as categorias: 1) Acolhimento } \\
\text { e relacionamento terapêutico como } \\
\text { instrumentos para fortalecimento de } \\
\text { vínculo; e 2) Terapia medicamentosa } \\
\text { e contenção: interface entre proteção, } \\
\text { estabelecimento de limites e outros } \\
\text { desafios para o cuidado. }\end{array}$ \\
\hline $\begin{array}{l}\text { Moraes, } \\
\text { Santos, Reis, } \\
\text { Silva, Vianna, } \\
\text { Kurimoto/2018. }{ }^{(16)}\end{array}$ & $\begin{array}{l}\text { A loucura e sua verdade } \\
\text { em questão: discursos } \\
\text { de profissionais de } \\
\text { enfermagem da atenção } \\
\text { hospitalar. }\end{array}$ & $\begin{array}{l}\text { Pesquisa de } \\
\text { abordagem } \\
\text { qualitativa, } \\
\text { de caráter } \\
\text { exploratório. }\end{array}$ & $\begin{array}{l}\text { Analisar os discursos } \\
\text { de profissionais de } \\
\text { enfermagem de uma } \\
\text { instituição hospitalar } \\
\text { acerca da loucura } \\
\text { e do cuidado de } \\
\text { enfermagem voltado } \\
\text { a pessoas com } \\
\text { sofrimento mental. }\end{array}$ & $\begin{array}{l}\text { Emergiram duas categorias: (1) } \\
\text { Concepções e causalidades: entre } \\
\text { o concreto da teoria e o abstrato da } \\
\text { experiência; na qual discute-se o } \\
\text { silenciamento da experiência diante da } \\
\text { teoria que acaba por prevalecer quando se } \\
\text { busca saber o que é a loucura. (2) A (in) } \\
\text { visibilidade revisitada ou a exclusão como } \\
\text { regra na qual a invisibilidade da loucura } \\
\text { reaparece na forma da loucura falsa. }\end{array}$ \\
\hline $\begin{array}{l}\text { Nicacio, Toledo, } \\
\text { Garcia/2018. }{ }^{(12)}\end{array}$ & $\begin{array}{l}\text { Da alienação à clínica } \\
\text { da enfermagem: } \\
\text { cuidado aos pacientes } \\
\text { psiquiátricos com } \\
\text { comorbidade. }\end{array}$ & $\begin{array}{l}\text { Estudo qualitativo } \\
\text { embasado no } \\
\text { referencial do } \\
\text { materialismo } \\
\text { histórico e } \\
\text { dialético. }\end{array}$ & $\begin{array}{l}\text { Conhecer como } \\
\text { os enfermeiros } \\
\text { de saúde mental } \\
\text { cuidam de pacientes } \\
\text { psiquiátricos com } \\
\text { comorbidades } \\
\text { clínicas. }\end{array}$ & $\begin{array}{l}\text { A atuação dos enfermeiros é marcada } \\
\text { pela dialética entre saber e não-saber, } \\
\text { movimento que revelou duas categorias: } \\
\text { clínica da enfermagem psiquiátrica; e } \\
\text { alienação e subordinação do enfermeiro no } \\
\text { processo de cuidar. }\end{array}$ \\
\hline
\end{tabular}




\begin{tabular}{|c|c|c|c|c|}
\hline Sora/2018. ${ }^{(20)}$ & $\begin{array}{l}\text { O cuidado de } \\
\text { enfermagem na } \\
\text { dimensão espiritual aos } \\
\text { pacientes em sofrimento } \\
\text { psiquícos numa } \\
\text { unidade de internação } \\
\text { psiquiátrica }\end{array}$ & $\begin{array}{l}\text { Estudo descritivo, } \\
\text { exploratório, } \\
\text { com abordagem } \\
\text { qualitativa. }\end{array}$ & $\begin{array}{l}\text { Objetivo geral: } \\
\text { "compreender } \\
\text { o significado da } \\
\text { espiritualidade e } \\
\text { suas articulações } \\
\text { experienciadas } \\
\text { pelo enfermeiro no } \\
\text { cuidado em saúde } \\
\text { mental como subsídio } \\
\text { de intervenção } \\
\text { ao paciente em } \\
\text { sofrimento psíquico" }\end{array}$ & $\begin{array}{l}\text { Cuidar de um outro que padece de } \\
\text { algum comprometimento psíquico, requer } \\
\text { além das habilidades e competências } \\
\text { inerentes à função, o desenvolvimento de } \\
\text { conhecimentos que torne este profissional } \\
\text { empático a este sofrimento. }\end{array}$ \\
\hline $\begin{array}{l}\text { Alves, Santos, } \\
\text { Oliveira, } \\
\text { Yamaguchi/2018. } \\
\text { (22) }\end{array}$ & $\begin{array}{l}\text { Serviços de saúde } \\
\text { mental: percepção } \\
\text { da enfermagem em } \\
\text { relação à sobrecarga e } \\
\text { condições de trabalho. }\end{array}$ & $\begin{array}{l}\text { Estudo descritivo, } \\
\text { analítico e } \\
\text { exploratório. }\end{array}$ & $\begin{array}{l}\text { Conhecer a } \\
\text { percepção dos } \\
\text { profissionais de } \\
\text { enfermagem em } \\
\text { relação à sobrecarga } \\
\text { e condições de } \\
\text { trabalho em serviços } \\
\text { psiquiátricos } \\
\text { hospitalares. }\end{array}$ & $\begin{array}{l}\text { Da análise de conteúdo emergiram três } \\
\text { categorias: As causas da sobrecarga } \\
\text { de trabalho; Aspectos que aliviam a } \\
\text { sobrecarga; Mudanças propostas para } \\
\text { diminuir a sobrecarga. }\end{array}$ \\
\hline Silva/2017. ${ }^{(15)}$ & $\begin{array}{l}\text { Centro de Atenção } \\
\text { Psicossocial III: } \\
\text { construção e } \\
\text { desenvolvimento das } \\
\text { ações de enfermagem. }\end{array}$ & $\begin{array}{l}\text { Estudo qualitativo } \\
\text { de abordagem } \\
\text { descritiva e } \\
\text { exploratória. }\end{array}$ & $\begin{array}{l}\text { Caracterizar a equipe } \\
\text { de enfermagem em } \\
\text { um Centro de Atenção } \\
\text { Psicossocial III do } \\
\text { município do Rio de } \\
\text { Janeiro; descrever } \\
\text { as ações realizadas } \\
\text { pela equipe de } \\
\text { enfermagem neste } \\
\text { Centro. }\end{array}$ & $\begin{array}{l}\text { Os profissionais de enfermagem } \\
\text { desenvolvem ações que incluem os } \\
\text { cuidados elementares de enfermagem } \\
\text { e cuidados voltados para a reabilitação } \\
\text { psicossocial. A equipe de enfermagem } \\
\text { realiza atividades interna no CAPS e } \\
\text { atividades extramuros, como matriciamento } \\
\text { e visita domiciliar. }\end{array}$ \\
\hline $\begin{array}{l}\text { Oliveira, } \\
\text { Schneider, } \\
\text { Santos, Pinho, } \\
\text { Piloti, Lavall/2017. } \\
\text { (19) }\end{array}$ & $\begin{array}{l}\text { Cuidados de } \\
\text { enfermagem a pacientes } \\
\text { com risco de suicídio. }\end{array}$ & $\begin{array}{l}\text { Estudo qualitativo, } \\
\text { descritivo. }\end{array}$ & $\begin{array}{l}\text { Identificar ações } \\
\text { de cuidado de } \\
\text { enfermagem ao } \\
\text { paciente com risco } \\
\text { de suicídio internado } \\
\text { em uma Unidade } \\
\text { de Internação } \\
\text { Psiquiátrica do Sul do } \\
\text { Brasil. }\end{array}$ & $\begin{array}{l}\text { Formação de vínculos e estabelecimento } \\
\text { de contrato terapêutico fazem parte do } \\
\text { cuidado mais singular, exercido tanto por } \\
\text { técnicos como por enfermeiros, no sentido } \\
\text { de conhecer melhor as experiências de } \\
\text { vida dos pacientes e ajudá-los a lidar com o } \\
\text { risco de suicídio. Em relação à organização } \\
\text { das rotinas, cabe ao enfermeiro esse } \\
\text { processo, de forma a oportunizar que o } \\
\text { vínculo e o contrato terapêutico se efetivem } \\
\text { no cotidiano da internação. }\end{array}$ \\
\hline $\begin{array}{l}\text { Dutra, Bossato, } \\
\text { Oliveira/2017. }\end{array}$ & $\begin{array}{l}\text { Mediar a autonomia: um } \\
\text { cuidado essencial em } \\
\text { saúde mental. }\end{array}$ & $\begin{array}{l}\text { Pesquisa } \\
\text { Convergente- } \\
\text { Assistencial, } \\
\text { com observação } \\
\text { e entrevista } \\
\text { semiestruturada. }\end{array}$ & $\begin{array}{l}\text { Conhecer as práticas } \\
\text { da Enfermagem, } \\
\text { naquele cenário do } \\
\text { serviço. }\end{array}$ & $\begin{array}{l}\text { Autonomia apresenta-se como um cuidado } \\
\text { que possibilita ao usuário ser o protagonista } \\
\text { da sua vida, reconhecendo seus limites } \\
\text { e suas possibilidades. Mesmo com o } \\
\text { transtorno mental as potencialidades dos } \\
\text { usuários devem ser reconhecidas. }\end{array}$ \\
\hline $\begin{array}{l}\text { Oliveira, Garcia, } \\
\text { Toledo/2017. }{ }^{(14)}\end{array}$ & $\begin{array}{l}\text { Padrões de } \\
\text { conhecimento utilizados } \\
\text { por enfermeiros no } \\
\text { cuidado ao paciente em } \\
\text { primeiro surto psicótico. }\end{array}$ & $\begin{array}{l}\text { Estudo qualitativo } \\
\text { de abordagem } \\
\text { fenomenográfica. }\end{array}$ & $\begin{array}{l}\text { Conhecer como o } \\
\text { enfermeiro realiza } \\
\text { o cuidado de } \\
\text { enfermagem ao } \\
\text { paciente em primeiro } \\
\text { surto psicótico e } \\
\text { identificar os padrões } \\
\text { de conhecimento } \\
\text { de Bárbara Carper } \\
\text { utilizados nessa ação. }\end{array}$ & $\begin{array}{l}\text { No cuidado de enfermagem ao paciente em } \\
\text { primeiro surto psicótico identificaram-se os } \\
\text { padrões de conhecimento em enfermagem } \\
\text { (empírico, estético, ético e pessoal) de } \\
\text { Bárbara Carper. }\end{array}$ \\
\hline
\end{tabular}




\begin{tabular}{|c|c|c|c|c|}
\hline $\begin{array}{l}\text { Tavares, } \\
\text { Gama, Souza, } \\
\text { Paiva, Silveira, } \\
\text { Mattos/2016. }\end{array}$ & $\begin{array}{l}\text { Competências } \\
\text { específicas do } \\
\text { enfermeiro de saúde } \\
\text { mental enfatizadas no } \\
\text { ensino de graduação em } \\
\text { enfermagem. }\end{array}$ & $\begin{array}{l}\text { Estudo qualitativo, } \\
\text { descritivo e } \\
\text { exploratório. }\end{array}$ & $\begin{array}{l}\text { Descrever o perfil } \\
\text { sociodemográfico } \\
\text { dos docentes da } \\
\text { área de enfermagem } \\
\text { de saúde mental } \\
\text { das instituições } \\
\text { públicas de ensino } \\
\text { superior do Rio de } \\
\text { Janeiro; Discutir } \\
\text { as competências } \\
\text { específicas do } \\
\text { enfermeiro de saúde } \\
\text { mental enfatizadas } \\
\text { pelos docentes no } \\
\text { curso de graduação } \\
\text { em enfermagem. }\end{array}$ & $\begin{array}{l}\text { Os docentes descrevem como } \\
\text { competências específicas do enfermeiro } \\
\text { de saúde mental: clínica do sujeito; } \\
\text { escuta sensível; comunicação terapêutica; } \\
\text { trabalho em equipe; autoconhecimento; } \\
\text { reforma psiquiátrica; atenção à família; } \\
\text { sistematização da assistência de } \\
\text { enfermagem; inovação; saber lidar com } \\
\text { a diferença e estigmas; desenvolver a } \\
\text { própria personalidade. Contudo, indicam } \\
\text { que o ensino não está orientado por } \\
\text { competências. }\end{array}$ \\
\hline $\begin{array}{l}\text { Moll, Mendes, } \\
\text { Ventura, } \\
\text { Mendes/2016. }{ }^{(24)}\end{array}$ & $\begin{array}{l}\text { Os cuidados de } \\
\text { enfermagem e o } \\
\text { exercício dos direitos } \\
\text { humanos: Uma análise } \\
\text { a partir de realidade em } \\
\text { Portugal. }\end{array}$ & $\begin{array}{l}\text { Observação } \\
\text { indireta. }\end{array}$ & $\begin{array}{l}\text { Descrever a } \\
\text { prestação de } \\
\text { cuidados de } \\
\text { enfermagem em } \\
\text { serviços de psiquiatria } \\
\text { para adultos de uma } \\
\text { cidade de Portugal, } \\
\text { na perspectiva do } \\
\text { exercício dos direitos } \\
\text { humanos. }\end{array}$ & $\begin{array}{l}\text { Foram identificadas as seguintes } \\
\text { unidades temáticas: acolhimento } \\
\text { dos pacientes na admissão; plano } \\
\text { assistencial de enfermagem; abordagem } \\
\text { familiar e estratégias de inserção social } \\
\text { desenvolvidas pelos enfermeiros. De } \\
\text { maneira geral, os enfermeiros valorizam as } \\
\text { dimensões preventivas, educativas, sociais } \\
\text { e assistenciais ao prestar cuidados, mas } \\
\text { não há a inclusão da família na terapêutica. }\end{array}$ \\
\hline $\begin{array}{l}\text { Muniz, Tavares, } \\
\text { Abrahão, } \\
\text { Souza/2015. }{ }^{(18)}\end{array}$ & $\begin{array}{l}\text { A assistência de } \\
\text { enfermagem em tempos } \\
\text { de reforma pisquiátrica. }\end{array}$ & Reflexão teórica. & $\begin{array}{l}\text { O objetivo foi } \\
\text { propor uma } \\
\text { reflexão a respeito } \\
\text { da assistência de } \\
\text { Enfermagem em } \\
\text { Saúde Mental e } \\
\text { Psiquiátrica. }\end{array}$ & $\begin{array}{l}\text { Sugiram um caminho para a equipe de } \\
\text { enfermagem, no contexto da atenção } \\
\text { Psicossocial, para que se supere } \\
\text { a assistência restrita à vigília, às } \\
\text { contenções e às injeções, procurando a } \\
\text { contextualização do cuidado com a lógica } \\
\text { da Reforma Psiquiátrica. }\end{array}$ \\
\hline $\begin{array}{l}\text { Lima, Vieira, } \\
\text { Silveira/2015. }{ }^{(13)}\end{array}$ & $\begin{array}{l}\text { A escuta terapêutica } \\
\text { no cuidado clínico de } \\
\text { enfermagem em saúde } \\
\text { mental. }\end{array}$ & $\begin{array}{l}\text { Estudo de } \\
\text { abordagem } \\
\text { qualitativa. }\end{array}$ & $\begin{array}{l}\text { Compreender a } \\
\text { concepção da } \\
\text { escuta terapêutica } \\
\text { no cuidado clínico } \\
\text { de enfermagem em } \\
\text { saúde mental. }\end{array}$ & $\begin{array}{l}\text { A prática da escuta destoa dos princípios da } \\
\text { Reforma Psiquiátrica, pois não possibilita } \\
\text { a inserção do sujeito no processo de } \\
\text { cuidar e desconsidera a sua fala enquanto } \\
\text { expressão da sua existência-sofrimento. } \\
\text { Apesar de conter elementos do referencial } \\
\text { psicossocial, na prática, a escuta se limita } \\
\text { a abordar o sofrimento psíquico sem } \\
\text { reconhecer o sujeito que sofre. }\end{array}$ \\
\hline $\begin{array}{l}\text { Silva, Terra, } \\
\text { Leite, Freitas, Ely, } \\
\text { Xavier/2015. }\end{array}$ & $\begin{array}{l}\text { Enfermagem e cuidado } \\
\text { de si no mundo do } \\
\text { cuidado em psiquiatria. }\end{array}$ & Estudo qualitativo. & $\begin{array}{l}\text { Compreender o } \\
\text { cuidado de si dos } \\
\text { profissionais de } \\
\text { enfermagem em } \\
\text { saúde mental. }\end{array}$ & $\begin{array}{l}\text { O mundo da psiquiatria foi a grande } \\
\text { categoria emergida do estudo. }\end{array}$ \\
\hline
\end{tabular}

\section{QUADRO 1 - Principais dados dos artigos incluídos na pesquisa. Brasília-DF, Brasil, 2019.}

\section{DISCUSSÃO}

Inicialmente, a atuação da enfermagem em saúde mental se baseia no relacionamento entre enfermeiro e paciente, e se constitui apoiado no encontro frequente, na continuidade do tratamento e na formação do vínculo. $O$ prosseguimento é que permite a relação e beneficia o reconhecimento de modificações patológicas. Além disto, foi constatado que há um olhar fragmentado do enfermeiro na assistência psiquiátrica, onde tratam o corpo e a mente como partes separadas, dando mais importância aos fatores mentais, dificultando a realização dos cuidados biológicos (ou às necessidades biológicas e fisiológicas). ${ }^{(12-13 ; 28)}$

Evidencia-se por meio de entrevista a enfermeiros que as funções desses profissionais no Centro de Atenção Psicossocial (CAPS) são entrepostas pela dependên- 
cia do outro, não praticando a autonomia, muitas vezes sendo dependente dos profissionais médicos, mostrando desconhecimento do regime terapêutico, a fragmentação da assistência, tornando abstrusa a continuação do tratamento. $O$ enfermeiro acaba sentido dificuldade em realizar sua função, pois the é cobrado que realize múltiplas tarefas, até mesmo além das atribuições do seu ambiente de trabalho. ${ }^{(12-13)}$

Pontua-se nesta ótica, que o cuidado ao paciente no primeiro surto psicótico está relacionado ao controle de sinais vitais e a sintomatologia patológica. Os profissionais relatam que a assistência ao paciente ao primeiro surto está mais associada às experiências vividas do que a um cuidado alicerçado técnico-cientificamente e que quando utilizam teorias, eles as combinam e as elegem de acordo com a facilidade de realização. Apesar disso, os profissionais procuram utilizar de elementos da psicanálise na assistência, porém, erroneamente ligando ao ponto de vista comportamental pautado nas necessidades humanas básicas. ${ }^{(14 ; 30)}$

Infere-se que os sentimentos dos enfermeiros pertinentes ao cuidado prestado aos pacientes em primeiro surto psicótico incluem medo, insegurança e ainda a tranquilidade e empatia. Há uma busca por compreender o potencial e limitações da assistência prestada. Nos argumentos, o apoio emocional e escuta ativa aparenta não ser ponderados uma vez que as atividades continuam mediadas no modelo biomédico, tendo como intervenções somente prescrições medicamentosas, normatização de comportamentos impróprios e adesão de métodos pedagógicos. Em alguns estudos é apresentado que os enfermeiros atentam para a responsabilidade da família como aquela que encaminha aos serviços e informa os sintomas do paciente durante a entrevista. ${ }^{(14 ; 13)}$

Indica-se que o que levam os profissionais a se inserirem na área de saúde mental varia desde as experiências prévias, até a necessidade de um vínculo empregatício. Apesar dos enfermeiros e técnicos de enfermagem afirmarem possuir conhecimento da importância da atuação multiprofissional, esses referem ter igualdade entre o cuidado prestado por cada categoria profissional, anulando a atuação específica que compete a cada classe dentro da equipe de enfermagem. Entre as ações realizadas interna e externamente nos CAPS por esta equipe, estão: acolhimento/convivência, oficinas, reuniões técnicas, visita domiciliar, acompanhamento do território e matriciamento. ${ }^{(15 ; 31)}$

Indagaram-se profissionais de enfermagem acerca de suas concepções sobre a loucura e os cuidados prestados nos transtornos mentais. Em relação à visão da etiologia do sofrimento mental, foram relatadas diversas causas, como carga hereditária, eventos traumáticos, uso de drogas, problemas ambientais e emocionais, desilusões amo- rosas, luto, perda do equilíbrio, fatores sociais e fatores espirituais. Houve abordagens da loucura como inerente a qualquer pessoa, como algo difícil, mal, que lhes causava tristeza, como um mal incurável, "mal do século". Apesar das diferenças individuais de cada paciente, o cuidado se torna prazeroso e trabalhoso e assim como em outro estudo os profissionais veem os pacientes psiquiátricos como doentes que precisa de cuidados. ${ }^{16,17}$ Desta forma, torna-se essencial que $\circ$ profissional de enfermagem se aproxime ao indivíduo com transtorno psíquico, e não somente ao seu diagnóstico. ${ }^{(18)}$

Ratifica-se que nesse cenário alguns profissionais veem os dependentes químicos não como doentes, mas como pessoas que procuraram estar naquela situação, "uma loucura falsa", desmerecidos de cuidado. Dentro desse contexto permeiam o medo e a insegurança e apesar de considerarem as queixas dos pacientes, os profissionais acabam se tornando o centro, rebaixando as percepções do indivíduo a ser cuidado. ${ }^{(16)}$

Evidenciou-se que em uma pesquisa realizada com profissionais de enfermagem que atuam na área de saúde mental, especialmente com pacientes com Transtorno de Personalidade Borderline (TPB), os participantes do estudo referiram que as atividades exercidas na admissão do paciente são acolhimento, entrevista e apresentação do espaço físico da unidade de internação. Neste sentido os profissionais declararam ter dificuldades na relação terapêutica com o doente mental, que é preciso dispor de destreza e paciência para enfrentar os eventuais episódios que acontecem no decorrer das internações do paciente TPB e que apresentam desconfortos expressos em dificuldades de comunicação e realização de procedimentos, desconfiança com o paciente e fatores de suas próprias concepções morais. ${ }^{(17)}$

Enfatizam ainda, a ideia de que o paciente com TPB é insistente, manipulador, que possui emocional inconstante, farsante, colérico, que está sempre em busca da atenção para si e que não expressa precisamente seus sentimentos. Esses profissionais realizam contenção mecânica e administram medicamentos quando necessário e, por falta de profissionais, deixam que outros pacientes também participem. Não mencionaram a realização da assistência antes e após a contenção. Os participantes da pesquisa trazem as concepções de que suas maiores dificuldades no cuidado ao paciente com TPB incluem desproporções na estrutura física, carência de recursos humanos, falta de assistência psicológica a esses profissionais e de capacitação, o que resulta em despreparo e insegurança para realização de suas atividades assistenciais. ${ }^{(17)}$

Identificou-se a respeito do risco de suicídio, através de entrevista com profissionais de enfermagem, que os cuidados mais efetivos na prevenção ao suicídio se resu- 
mem em três: formação de vinculo com o paciente, demonstrando interesse e realizando escuta ativa para ter o conhecimento de suas apreensões e demais sentimentos; estabelecimento de contrato terapêutico, criando um compromisso de assistência para realização de práticas clínicas; e organização da rotina assistencial da equipe, estabelecendo rotinas, possibilitando a alternância da observação ao paciente e realizando a remoção de utensílios na unidade de internação que pode ser um meio para que o paciente cometa $o$ ato suicida. Nesse sentido, a equipe de enfermagem enfrenta frequentemente o processo de morte e lida com o sofrimento, sentimentos, anseios e diversas perdas por parte dos pacientes. ${ }^{(19)}$

Emerge-se também a concepção do enfermeiro no cuidado a dimensão espiritual dos doentes mentais, onde profissionais de enfermagem de um hospital psiquiátrico foram indagados acerca da definição de espiritualidade e foram encontradas respostas como crença/fé, religiosidade, estado de espirito, conforto e paz, sintonia, bem -estar e respeito ao próximo. Neste âmbito, é necessário capacitação para que esses profissionais possam atuar ampliando horizontes para que cada paciente trilhe a procura do sentido pessoal. ${ }^{(20)}$

Nota-se a importância da adoção de meios para a qualificação dos profissionais no lidar com a dimensão espiritual dos pacientes, já que esta temática não é abordada no estudo acadêmico e é de difícil entendimento e introdução na assistência ao indivíduo com sofrimento mental.A graduação é responsável pela formação profissional, capacitando-os para trabalhar nas diversas áreas possíveis de atuação, sendo treinados para enfrentar eficientemente situações de estresse e conflitos. Porém, as instituições preocupam mais com o ensino das atividades essenciais da enfermagem, com o conhecimento científico e prático e anulam o direcionamento assistencial para a dimensão espiritual. ${ }^{(20)}$

Contatou-se que, apesar dos inúmeros estudos que relatam a carência no ensino de saúde mental, em pesquisa feita com docentes dessa disciplina sobre as competências de enfermagem que são focadas na graduação foi obtida que a orientação pedagógica local não era pautada em competências, mas entre os temas abordados no ensino da disciplina incluem: "clínica do sujeito, escuta sensível comunicação terapêutica, trabalho em equipe, autoconhecimento, atenção à família, sistematização da assistência de enfermagem, inovação, saber lidar com a diferença e estigmas e desenvolvimento da própria personalidade".(21)

Sabe-se que a sobrecarga de trabalho se faz presente nos serviços de saúde mental e os profissionais de enfermagem estão submetidos a vários elementos que a provoca, trazendo também condições desfavoráveis de trabalho. A partir das concepções dos profissionais de enfermagem, as maiores causas de sobrecarga estão relacionadas com o cuidado ao paciente, espaço físico de trabalho e diminuição numeral dos recursos humanos. Logo, em sua visão, o que atenua essa sobrecarga é o preenchimento do quadro de funcionários, melhoria salarial, aperfeiçoamento da infraestrutura, treinamento/capacitação, diminuição da carga horária, a assistência prestada, o diálogo com o paciente e o trabalho em equipe. ${ }^{(22)}$ Frequentemente, os trabalhadores desta área possuem mais de um emprego, diminuindo o tempo de descanso e família. Com as jornadas de trabalho aumentadas, há um aglomerado de atribuições acarretando o estresse emocional. (15)

Evidenciou-se que a preocupação dos profissionais diante das internações dos pacientes é percebida e a instituição, mesmo após a reestruturação com a reforma psiquiátrica, ainda demonstra ser um local segregado, isolado, despersonalizado e encarcerado. Para mais, surgem-se a vivência em saúde mental como geradora de angústia, estresse, aflição, sofrimento e insegurança, mas também como causadora de motivação para autorreflexão, aquisição de conhecimento e amadurecimento. Desvela-se que, o que motiva o profissional a ser cuidador da saúde mental vai além de experiências próprias e familiares, trazendo sentimentos e medos incompreensíveis ao sujeito. ${ }^{(23)}$

Compreende-se que a mudança do modelo assistencial hospitalocêntrico para uma assistência psicossocial aos transtornos psicóticos no Brasil pode ser difícil aos profissionais de enfermagem. A complexidade consiste em entender a importância que as atribuições presentes na Lei do exercício profissional da Enfermagem (lei $n^{\circ} 7.498 / 86$ ) exercem no tratamento ao individuo com sofrimento mental. A assistência psiquiátrica deve ter um olhar holístico, abordando a pessoa com sofrimento psíquico em todas as suas dimensões (biopsicossocial), definindo um cuidado mais ampliado, não dando enfoque somente nos fatores psicológicos. ${ }^{(15 ; 24)}$

Aponta-se neste estudo que é necessário manejar cada caso, considerando o sujeito como cidadão, na sua integridade e capacidade de autocuidado. Os enfermeiros apoiam a autonomia mediada e o investimento no paciente para que haja uma construção de cada história de modo pessoal, tornando-os independentes, construindo novas relações, criando decisão própria e responsabilização como ser social e cidadão que são. ${ }^{(25)}$

Entende-se que o cuidado de si neste âmbito é como uma ligação entre o cuidado com o próximo e a atenção consigo mesmo, aumentando o vínculo com os colegas de trabalho, pacientes e familiares. Ao inquirir novas maneiras de se prestar a assistência, os profissionais esbarram nos mitos e preconceitos na sociedade que envolvem o transtorno mental, o indivíduo e o profissional que tra- 
balha nesta área. No relacionamento com o outro, o desenvolvimento pessoal e profissional se torna possível e ao mesmo tempo sente-se fragilidade, pois traz conflitos estressantes, tensão, inseguridade e temor. ${ }^{(23)}$

\section{CONCLUSÃO}

Evidenciou-se que acerca das percepções dos enfermeiros, o cuidado do paciente com transtorno mental ainda é muito limitado, fragmentado, falta capacitação profissional e melhor definição de papéis. Os enfermeiros têm sentimentos de medo, esgotamento, insegurança, comodidade, estresse, angústia e sofrimentos no decorrer da assistência e em contrapartida utilizam da empatia, escuta ativa, preocupação com o paciente, olhar holístico e tentativa de reinserção do doente mental na sociedade. Apesar disso, de- monstram interesse de melhorias assistenciais, descoberta de suas limitações e aperfeiçoamento do trabalho.

Evidenciou-se a necessidade de uma maior atenção aos profissionais de saúde mental, oferecendo suporte psicológico, uma maior abrangência das competências de ensino na graduação em saúde mental e psiquiátrica e melhorias relativas às condições de trabalho.

Ressalta-se que há carência de pesquisas que trate a temática sob a ótica do profissional enfermeiro na saúde mental, o tema carece de maior abrangência quanto a estudos qualitativos sobre a divergência da percepção dos enfermeiros em diferentes áreas de atuação como na atenção primária, secundária e terciária trazendo assim concepções de diferentes categorias, visando obter mais referencial teórico sobre o tema. 


\section{REFERÊNCIAS}

I. Zanetti ACG, Carmo MA, Tressoldi LS, Vedana KGG, Giacon BCC, Martin IS. Intervenções familiares em pacientes no primeiro episódio psicótico: evidências da literatura. Rev enferm UFPE on line [internet]. 2017 jul [cited 2019 May 25]; I I (supl.7):297I-2978. DOI: I0.5205/reuol.II00798133-3-SM.II07sup201719.

2. Araújo LMC, Godoy EFM, Botti NCL. Situações presentes na crise de pacientes psicóticos. Arq bras psicol [Internet]. 2017 [cited 2019 Mai 25]; 69(2):I38-I52. Disponível em: http://pepsic.bvsalud.org/pdf/arbp/v69n2/10.pdf.

3. Organização Mundial da Saúde. CID-I0 Classificação Estatística Internacional de Doenças e Problemas Relacionados à Saúde. 10a rev. São Paulo: Universidade de São Paulo; 1997. vol. I.

4. Murcho N, Pacheco E, Jesus SN. Transtornos mentais comuns nos Cuidados de Saúde Primários: Um estudo de revisão. Rev port enferm saúde mental [Internet]. 2016 Jun [cited 2019 Oct 27]; (I5): 30-36. DOI: http://dx.doi. org/10.19131/rpesm.0129.

5. Fernandes MA, Sousa KHJF, Andrade PCA, Carvalho LCS, Pereira DBD, Silva BJM. Transtorno afetivo bipolar, episódio atual maníaco com sintomas psicóticos e o cuidar em enfermagem. Rev enferm UFPE on line [internet]. 2016 fev [Cited 2019 oct 05]; I0(2):669-674. DOI: 10.5205/ reuol.8557-7466 I-I-SMI00220I638.

6. Kaplan HI, Sadock BJ. Compêndio de psiquiatria: ciências do comportamento e psiquiatria clínica. I I. ed. Porto Alegre: Artes médicas, 2017.

7. Duarte MLC, Carvalho J, Brentano V. Percepção dos familiares acerca do grupo de apoio realizado em uma unidade de internação psiquiátrica. Rev Gaúch Enferm [Internet]. 2018 [cited 2019 Mar 30]; 39: e2017-0I I5. DOI: https://doi. org/I0.1590/1983-I447.2018.2017-0II5.

8. Nascimento KC, Kolhs M, Mella S, Berra E, Olschowsky A, Guimarães AN. O desafio familiar no cuidado às pessoas acometidas por transtorno mental. Rev enferm UFPE on line [internet].2016 mar [cited 2019 Mar 30]; 10(3):940-8. DOI: 10.5205/reuol.8702-76273-4-SM.100320160I.

9. Dias GC, Furegato ARF. Impacto do trabalho e satisfação da equipe multiprofissional de um hospital psiquiátrico. Rev enferm UER] [internet]. 2016 [Cited 2019 oct 26]; 24(I):e8/64. DOI: http://dx.doi.org//0.12957/ reuerj.2016.8164.

10. Garcia APRF, Freitas MIP, Lamas JLT, Toledo VP. Nursing process in mental health: an integrative literature review. Rev Bras Enferm [Internet]. 2017 [Cited 2019 oct 27]; 70(I):209-18. DOI: http://dx.doi.org//0.1590/0034-7/672016-0031.

I I. Santos AG, Monteiro CFS, Feitosa CDA, Veloso C, Nogueira LT, Andrade EMLR. Tipos de transtornos mentais não psicóticos em mulheres adultas violentadas por parceiro íntimo: uma revisão integrativa. Rev esc enferm USP [Inter- net]. 2018 may 24 [cited 2019 Oct 27]; 52: e03328. DOI: http://dx.doi.org// 0.I590/s I 980-220x20 I 7030203328.

12. Nicacio TR, Toledo VP, Garcia APRF. From alienation to the nursing clinic: care of patients with psychiatric comorbidity. Rev Bras Enferm [Internet]. 2018 [cited 2019 Oct 27]; 7I(Suppl 5): 2229-2236. DOI: http://dx.doi. org/l0.1590/0034-7I67-20I7-0930.

13. Lima DWC,Vieira AN, Silveira LC.A escuta terapêutica no cuidado clínico de enfermagem em saúde mental. Texto contexto - enferm [Internet]. 2015 Mar [cited 2019 Oct 27]; 24(I): I54-I60. DOI: http://dx.doi.org/I0.I590/0 I0407072015002450013.

14. Oliveira A, Garcia APRF,Toledo VP. Padrões de conhecimento utilizados por enfermeiros no cuidado ao paciente em primeiro surto psicótico. Esc Anna Nery Rev Enferm [Internet]. 2017 [cited 2019 Oct 27]; 2 I (3): e20I7000I. DOI: http://dx.doi.org//0.1590/2 I77-9465-ean-2017-000I.

I5. Silva, TCS. Centro de Atenção Psicossocial III: construção e desenvolvimento das ações de enfermagem. Rev Pesqui (Univ Fed Estado Rio J, Online). 2017 [Cited 2019 Oct 26]; 125 f.: il. Disponível em: http://objdig.ufrj.br/5I/teses/852468.pdf.

16. Moraes LN, Santos E, Reis HFT, Silva MRA,Vianna PCM, Kurimoto TCS. A loucura e sua verdade em questão: Discursos de profissionais de enfermagem da atenção hospitalar. Rev port enferm saúde mental [Internet]. 2018 Jun [cited 2019 Oct 27]; (19): 27-36. DOI: http://dx.doi.org/l0.19131/ rpesm.0199.

17. Agnol ECD, Meazza SG, Guimarães AN, Vendruscolo C, Testoni AK. Cuidado de enfermagem às pessoas com transtorno de personalidade borderline na perspectiva freireana. Rev Gaúch Enferm [Internet]. 2019 [cited 2019 Oct 27]; 40: e20180084. DOI: http://dx.doi.org/10.1590//9831447.2019.20180084.

18. Muniz MP, Tavares CMM, Abrahão AL, Souza ÂC. A assistência de enfermagem em tempos de reforma psiquiátrica. Rev port enferm saúde mental [Internet]. 2015 Jun [cited 2019 oct 27]; (13): 6I-65. Disponível em: http://www.SciELO.mec.pt/pdf/rpesm/n I3/n I 3a08.pdf.

19. Oliveira GC, Schneider JF, Santos VBD, Pinho LB, Piloti DFW, Lavall E. Cuidados de enfermagem a pacientes com risco de suicídio. Ciênc cuid saúde [Internet]. 2017 [cited 2019 Oct 26]. DOI: 10.4025/cienccuidsaude.v I6i2.37I82.

20. Sora, ABA. O cuidado de enfermagem na dimensão espiritual aos pacientes em sofrimento psíquicos numa unidade de internação psiquiátrica. Dissertação mestrado profissional em enfermagem assistencial. 2018 [cited 2019 Oct 26]. Disponível em: https://app.uff.br/riuff/bitstream/I/94I0/I/ Alcilea\%20Barbosa\%20de\%20Andrade\%20Sora.pdf.

21. Tavares CMM, Gama LN, Souza MMT, Paiva LM, Silveira PG, Mattos MMGR. Competências específicas do enfermeiro de saúde mental enfatizadas no ensino de graduação em enfermagem. Rev port enferm saúde mental [Internet]. 
2016 Out [cited 2019 Oct 27]; (spe4): 25-32. DOI: http:// dx.doi.org/l0.19131//rpesm.0137.

22. Alves SR, Santos RP, Oliveira RG, Yamaguchi MU. Mental health services: perception of nursing in relation to overload and working conditions. Rev Pesqui (Univ Fed Estado Rio J, Online) [Internet]. 2018 jan/mar [cited 2019 Oct 27]; I0(I):25-29. DOI: 10.9789/2I75-536I. 20I8.vI0il.25-29.

23. Silva AA, Terra MG, Leite MT, Freitas FF, Ely GZ, Xavier MS. Enfermagem e cuidado de si no mundo do cuidado em psiquiatria. Rev Pesqui (Univ Fed Estado Rio J, Online) [Internet]. 2015 [cited 2019 Oct 27]. DOI: 10.9789/2 175-536I. 20I5.v7il.20II-2020.

24. Moll MF, Mendes AC, Ventura CAA, Mendes IAC. Os cuidados de enfermagem e o exercício dos direitos humanos: Uma análise a partir de realidade em Portugal. Esc Anna Nery Rev Enferm [Internet]. 2016 June [cited 2019 Oct 27]; 20(2): 236-242. DOI: |0.5935/|4|4-8|45.2016003।.

25. Dutra VFD, Bossato HR, Oliveira RMP. Mediar a autonomia: um cuidado essencial em saúde mental. Esc Anna Nery Rev Enferm [Internet]. 2017 [cited 2019 Oct 27]; 21(3): e20160284. DOI: 10.1590/2 I77-9465-EAN-2016-0284.

26. Copelli FHS, Erdmann AL, Santos JLG. Entrepreneurship in Nursing: an integrative literature review. Rev Bras Enferm [Internet]. 2019;72(Suppl I):289-98. [ Thematic Issue: Work and Management in Nursing]. DOI: http://dx.doi. org//0.1590/0034-7167-2017-0523.

27. Souza MT, Silva MD, Carvalho R. Revisão integrativa: o que é e como fazer. Einstein [Internet]. 2010 [cited 2014 Dec I5];8(IPt I):102-6. Disponível em: http://astresmetodologias.com/material/O_que_e_RIL.pdf.

28. Nóbrega MPSS, Venzel CMM, Sales ES, Próspero AC. Ensino de enfermagem em saúde mental no brasil: perspectivas para a atenção primária à saúde. Texto Contexto Enferm [Internet]. 2020 [acesso MÊS ANO DIA]; 29:e2018044I. Disponivel em: http://dx.doi.org//0.1590//980-265XTCE-20I8-044I.

29. Araújo LMC., Godoy E.F.M., Botti N.C.L. Situações presentes na crise de pacientes psicóticos. Arquivos Brasileiros de Psicologia [Internet]. 2017 [acesso em 25 de março de 2020]; 69 (2): I38-152. Disponível em: http://pepsic.bvsalud. org/pdf/arbp/v69n2/10.pdf.

30. Neto AG, Tauro DVE. A psicose e saúde mental: impasses na contemporaneidade. Revista Psicologia e Saúde [Internet]. 2015 [acesso em 25 de março de 2020]; 7(2): 152-160. http://pepsic.bvsalud.org/pdf/rpsaude/v7n2/v7n2a09.pdf.

31. Gaino LV, Souza J, Cirineu CT, Tulimosky TD. O conceito de saúde mental para profissionais de saúde: um estudo transversal e qualitativo. SMAD, Rev. Eletrônica Saúde Mental Álcool Drog. [Internet]. 2018 [acesso em 20 de março de 2020]; 14(2):108-I 16. Disponível em: http://dx.doi. org/10.1 I606/issn. 1806-6976.smad.2018.149449.

Recebido: 2020-03-25 Aceito: 2020-05-05 